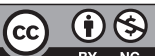

\title{
Construção histórica de um sistema dual de ensino e indefinição de fronteiras das redes pública e privada no Brasil
}

\author{
Historical construction of a dual system of education and \\ blurring of frontiers of public and private schools in Brazil
}

\section{Abdeljalil Akkari ${ }^{[a]}$, Camila Pompeu ${ }^{[b]}$, Ana Sheila Fernandes Costa ${ }^{[c]}$, Peri Mesquida ${ }^{[d]}$}

[a] Pesquisador/professor titular da Université de Genève (Unigenève), Suíça, e-mail: djalil98@gmail.com

[b] Doutoranda em Ciências da Educação, Université de Genève (Unigenève), Suíça, e-mail: camila. pompeu@uol.com.br

[c] Doutoranda em Ciências da Educação, Université de Genève (Unigenève), Suíça, e-mail: anasheilaf@yahoo.com.br

[d] Professor titular da Pontifícia Universidade Católica do Paraná (PUCPR), Curitiba, PR - Brasil, e-mail: mesquida.peri@gmail.com

\section{Resumo}

O presente artigo aborda a privatização da educação pública no Brasil com foco na indefinição de fronteiras entre as redes pública e privada. $O$ estudo parte de uma análise histórica da relação público/privado, evidenciando que essa dualidade é decorrente de um longo processo histórico do sistema educativo brasileiro. Tanto os jesuítas quanto 
outras instituições religiosas colocaram em prática trajetórias de ensino diferentes de acordo com a classe social para a qual era dirigido. Além disso, o artigo discute também o desenvolvimento de um poderoso setor privado, que além de reforçar sua presença no setor educacional, com papel fundamental na reprodução das elites, tem se beneficiado do financiamento público, produzindo um sistema educativo desigual. Trata-se, ainda, de argumentar que a indefinição de fronteiras entre esses setores de ensino passa por cinco mecanismos principais: a) a legislação favorável ao ensino privado; b) o financiamento público do setor privado; c) as parcerias público/privado; d) o fornecimento de material pedagógico formatado (apostila) para a rede de ensino público pelo setor privado; e) o trânsito de estudantes e professores do público para o privado e vice-versa. A partir dos dados apresentados, é discutida a possibilidade de uma verdadeira regulação das relações entre as redes pública e privada pelas políticas públicas educacionais.

Palavras-chave: Educação. Fronteiras. Público/privado.

\section{Abstract}

The present article discusses the privatization of public education in Brazil focusing on the undefined of frontiers between public and private schools. The study starts with a historical analysis of public-private relationship showing that this duality is the result of a long historical process of the Brazilian educational system. Both the Jesuits and other religious institutions put in place different trajectories of education according to social class for whom it was directed. In addition, the article also discusses the development of a powerful private sector and strengthen its presence in the educational sector, with key role in the reproduction of elites, has benefited from public funding, producing an unequal educational system. It is also to argue that the blurring of boundaries between the sectors of education through five main mechanisms: a) a suitable legislation supporting the private initiatives; b) a public financing for private legislations; c) increasing partnerships between public and private institutions; d) the supply of formatted pedagogic materials ('apostilas') by private institution to public schools; e) the swap of students and teachers from public to private schools. It finally discuss the possibility of building new public policies able to tackle structural educational inequalities.

Keywords: Education. Frontiers. Public/private. 


\section{Introdução}

Inúmeros estudos abordaram a privatização da educação pública no Brasil e em outras partes do mundo procurando mostrar o funcionamento da lógica do mercado no setor educacional. O papel das organizações internacionais, como o Banco Mundial e o FMI, no contexto dessa ofensiva neoliberal, foi amplamente analisado (ALTMANN, 2002). Neste trabalho, todavia, adotaremos uma perspectiva diferente: centraremos nossa atenção sobre a indefinição das fronteiras que deveriam separar o público do privado.

Dessa maneira, na primeira parte deste artigo discutiremos a relação entre escola pública e escola privada em uma perspectiva histórica. Analisaremos os diferentes grupos de pressão que favoreceram o surgimento de um poderoso setor privado (confessional e comercial) ao longo século XX e suas relações com movimentos políticos, sociais e educacionais.

A segunda parte do artigo apresentará a evolução da distribuição das matrículas entre as diferentes redes de ensino na última década. O setor privado tem reforçado sua presença e atualmente parece desfrutar do privilégio exclusivo de reprodução das elites no ensino fundamental e médio. No entanto, no ensino superior a rede privada, apesar de sua expansão quantitativa, se endereça especialmente às classes médias. Os filhos das elites frequentam, na maioria dos casos, a universidade pública, beneficiando-se da qualidade da educação recebida na rede privada, durante o ensino fundamental e médio, para passarem nos seletivos processos de entrada das universidades.

A terceira parte do artigo analisará a crescente indefinição dos limites entre as redes pública e privada. Para além do clássico financiamento público do ensino privado, outros mecanismos mais sutis podem ser observados: a compra pela rede pública de material pedagógico produzido pela rede privada (apostilas, por exemplo) e professores que acumulam cargos nas duas redes. Trata-se, portanto, de analisar, de um lado, em benefício de quem ocorre essa indefinição dos limites entre as redes de ensino; e, de outro, mostrar como esta se constitui no principal mecanismo de manutenção das desigualdades educacionais no Brasil. 
A quarta parte do artigo abordará a possibilidade de uma verdadeira regulação das relações entre as redes pública e privada pelas políticas públicas educacionais. Duas questões fundamentais serão abordadas: a primeira, se refere à eficácia do maciço investimento público atual na educação básica para melhorar a qualidade do ensino e para fazer voltar, ao menos uma parte, aas classes média e alta para a rede pública no ensino obrigatório; a segunda questão diz respeito às reformas em curso no vestibular e suas consequências sobre a estrutura atual de um sistema educativo em diferentes ritmos.

\section{A dualidade histórica do sistema educacional brasileiro}

O processo de escolarização no Brasil teve início em 1549, quando aportou no País a primeira expedição colonizadora enviada pela Coroa Portuguesa. Essa expedição trazia, além de colonos, artesãos e soldados, seis jesuítas, sendo quatro padres formados em Teologia na Universidade de Coimbra e dois estudantes de Teologia (MESQUIDA, 2009, p. 8). Imediatamente após terem desembarcado no País, os jesuítas deram início à sua missão de escolarizar a Colônia, fundando escolas para os índios (em especial para lhes ensinar ofícios) e colégios para a incipiente elite agrária de origem portuguesa. O dualismo, escolas para os menos favorecidos e colégios para a elite, irá marcar a história da educação no Brasil ao longo dos séculos, se refletindo em um duplo sistema de ensino.

A manutenção das escolas e dos colégios dos jesuítas se dava graças ao dízimo do orçamento da Ordem dos Templários sediada em Tomar, Portugal. Tratava-se, portanto, de um subsídio privado (MESQUIDA, 2009, p. 8). Dessa maneira, as instituições de ensino dos jesuítas no Brasil eram confessionais, mantidas por uma instituição privada e a serviço dos interesses do Estado (Coroa Portuguesa).

Durante 210 anos (1549-1759), os jesuítas foram os responsáveis pelo ensino na colônia latino-americana de Portugal, desenvolvendo um ensino dual, prático/utilitário, por meio das escolas para índios e filhos 
dos peões que trabalhavam para os donos das terras (escola básica); e propedêutico, pelos colégios que preparavam a prole da elite agrária para dar continuidade aos estudos na Europa, retornando depois de formada para exercer sua função de dirigente política na colônia (AZEVEDO, 1971).

A expulsão dos jesuítas, em 1759, pelo Marquês de Pombal, no quadro da tentativa de fazer medrar as ideias iluministas em Portugal e fazer o País sair do feudalismo e entrar no sistema capitalista europeu, criou um vazio na educação no Brasil, que durante quase três quartos de século ficou praticamente sem o ensino básico. Este somente será lembrado cinco anos após a proclamação da independência, por meio da Lei Geral, de 1827, que visava à criação de escolas primárias (BERGER, 1984).

No entanto, se houve um 'vazio' na educação básica, o mesmo não ocorreu com o preparo dos filhos da classe dirigente, que se beneficiaram da presença de preceptores, nas fazendas, preparando-os para a entrada em universidades portuguesas e francesas. Além disso, a independência política (1822) e o movimento republicano (a partir de 1870), no contexto das ideias liberais oriundas da França e dos Estados Unidos da América, abriram as portas do País para intervenções educativas privadas, seja de leigos, seja de instituições de ensino confessionais, católicas e protestantes, em especial essas últimas. Assim, os jesuítas retornaram em 1842, reiniciando suas atividades educativas. Ao mesmo tempo, o bispo de São Paulo, Dom Antonio Joaquim de Melo, fez um apelo (vocação) para que congregações femininas estrangeiras se estabelecessem criando colégios para moças. Dom Antonio de Melo chamou, ainda, ordens religiosas educadoras masculinas da Europa, franciscanos, dominicanos e beneditinos, para atuarem no sistema de ensino privado no Brasil (MESQUIDA, 1994; RAMALHO, 1976).

No entanto, os protestantes de origem missionária norte-americana, metodistas, presbiterianos e batistas, aproveitaram a onda liberal e a abertura proporcionada pela Lei n. 54, de 1868, que suprimiu o ensino secundário na Província de São Paulo, para se inserirem no espaço educativo brasileiro, a partir do final da segunda metade da década de 1860 . Esses protestantes fundaram, em especial, colégios para os filhos da elite 
republicana e da oligarquia agrária brasileira na região mais desenvolvida do País, a Região Sudeste, mas não esqueceram os filhos dos proletários, pois abriram escolas paroquiais nas periferias das cidades em processo de industrialização, onde eram ministradas as primeiras letras, mediante o pagamento de uma mensalidade considerada 'simbólica'. Essas escolas de primeiras letras filtravam os alunos considerados potencialmente dotados de espírito de iniciativa, futuros líderes dos trabalhadores, cooptando-os com bolsas de estudo para darem continuidade aos estudos em seus colégios no Brasil e nos seus Colleges e Universidades nos EUA, transformando-se em pastores protestantes ou profissionais liberais, defensores das ideias e dos valores norte-americanos, de acordo com as expectativas da elite republicana brasileira (MESQUIDA, 1994).

Os colégios protestantes traziam dos Estados Unidos da América uma educação considerada 'moderna' pela elite política brasileira, pois a prática pedagógica tinha como base o empirismo de Charles S. Peirce (18391954), e o pragmatismo de W. James (1842-1910), fontes do pensamento de John Dewey (1859-1952), desenvolvidos com o auxílio do método indutivo, apropriado, segundo a visão dessa liderança política, à formação de homens livres, democráticos, racionais e empreendedores (MESQUIDA, 1994).

Dessa maneira, o Estado brasileiro deixava nas mãos da iniciativa privada o ensino da elite, assumindo o papel de Estado educador para os filhos dos trabalhadores. Portanto, enquanto a elite brasileira, em especial na Região Sudeste, era formada em colégios confessionais/privados protestantes, e mesmo católicos, tendo acesso a uma educação apropriada à formação de dirigentes, os filhos dos trabalhadores recebiam do Estado uma educação de pouca qualidade ministrada na rede estatal de educação básica, uma educação capaz de formar trabalhadores dóceis e conformados (FRIGOTTO, 2001).

O desenvolvimento da industrialização, a partir da primeira metade do século XX, especialmente após a Primeira Guerra Mundial, exigiu a profissionalização dos trabalhadores, em particular nas cidades mais povoadas da Região Sudeste: Juiz de Fora (Minas Gerais), Rio de Janeiro (capital federal), São Paulo e Campinas (Estado de São Paulo). Houve, portanto, uma série de reformas regionais do ensino com o objetivo 
declarado de colocar a educação brasileira à 'altura do século', isto é, fazer as instituições de ensino responder à demanda por formação de mão de obra qualificada para empresas industriais, comerciais e de serviços.

Durante o governo de Getúlio Vargas (1930-1945), as 'leis orgânicas' foram endereçadas ao ensino básico (primário) e ao ensino intermediário: secundário, industrial, comercial. O ensino secundário, com o objetivo de formar os filhos das classes superiores para prosseguir os estudos em instituições de ensino superior (oferecidas principalmente por instituições de ensino privadas e/ou instituições privadas subsidiadas pelo governo, como o Sesi e o Senac); já o ensino industrial oferecia uma formação técnica para os filhos dos trabalhadores; e o ensino comercial tinha por objetivo formar mão de obra necessária para o setor de serviços da economia urbana.

O século XX foi marcado por essa dualidade histórica de escola estatal ${ }^{1}$ de má qualidade para as classes subalternas e instituições de ensino de boa e ótima qualidade, inseridas na rede privada, para a elite. Um dualismo que perdura até hoje e colabora para a manutenção de sistemas múltiplos de ensino, aumentando e perpetuando a distância entre as camadas sociais fundamentais que constituem a estrutura social brasileira.

Após esta breve análise histórica da relação entre os setores público e privado da educação, é cabível assinalar que este trabalho não subestima o progresso realizado no Brasil, durante as duas últimas décadas, em favor da educação dos mais desfavorecidos. Os programas lançados após a implantação da LDB (Lei 9.394/96) permitiram ao País oferecer oportunidade de acesso à educação de base para um contingente significativo de brasileiros e brasileiras. Além disso, o programa Bolsa Família² foi criado com a intenção de contribuir para a permanência das crianças na escola.

1 Durante o século XX, paralelamente à criação de colégios privados para a elite, várias iniciativas, visando à criação de escolas públicas de alto nível para formar as elites, foram implementadas no Estado de São Paulo (CUNHA, 2000).

2 O programa Bolsa Família, regulamentado pela Lei n. 10.836, de 9 de janeiro de 2004, tem por objetivo combater a fome, a miséria e promover a emancipação das famílias mais pobres do País. Por meio desse programa, o governo federal concede mensalmente benefícios em dinheiro para famílias mais necessitadas. 


\section{A expansão do setor privado}

Esta parte do artigo apresentará a evolução da distribuição das matrículas nas diferentes redes de ensino (pública e privada) nos últimos anos. No que concerne ao ensino fundamental, ${ }^{3}$ verificamos uma baixa no total das matrículas. No entanto, essa redução se refere apenas ao setor público. O setor privado passou por um ligeiro aumento, de acordo com os dados do Inep (2000a).

Mesmo que as matrículas da rede privada sejam modestas em relação às da rede pública, como mostram os dados do Inep (2000b), não podemos esquecer o caráter elitista da educação privada no Brasil. Segundo Curi e Menezes Filho (2009), 16\% dos jovens de 0 a 25 anos frequentam as escolas privadas. Esse percentual varia entre $18,5 \%$ no ensino fundamental (anos iniciais), 11\% no ensino fundamental (anos finais) e 15,5\% no ensino médio. Aproximadamente $80 \%$ das crianças provenientes das famílias mais ricas frequentam a rede privada, enquanto esse percentual é de apenas 3,5\% para as crianças das famílias mais pobres. O Estado do Rio de Janeiro e o Distrito Federal são as regiões onde o setor privado é mais desenvolvido, enquanto a Bahia e os Estados da Região Norte são aqueles em que o setor privado é menos desenvolvido. Curi e Menezes Filho (2009) demonstram que $80 \%$ dos alunos escolarizados na rede privada pertencem à categoria social de renda $\mathrm{A}$ e $5 \%$ são da classe social $\mathrm{E}$.

As famílias mais pobres destinam aproximadamente $10,6 \%$ de sua renda para pagar as mensalidades da rede privada, enquanto as famílias mais favorecidas gastam apenas 5\% (CURI; MENEZES FILHO, 2009). Portanto, optar pelo setor privado representa um grande peso no orçamento das famílias desfavorecidas.

A fim de oferecer uma educação que garanta o ingresso em instituições de ensino superior (IES) públicas, uma família pode gastar até

3 Em 2006, o antigo modelo (oito anos) do ensino fundamental foi alterado pela Lei 11.274/2006, que regulamentou a ampliação do ensino fundamental para nove anos (6-14 anos). A Lei tornou obrigatória a matrícula de crianças de seis anos. 
$\mathrm{R} \$ 2.756,00$ por mês no ensino médio. Esse valor se aproxima do que o governo gasta anualmente com um estudante do ensino médio nas escolas públicas. Podemos verificar que os valores variam conforme a região e a localização (capital ou interior). No Norte, esses valores variam de $\mathrm{R} \$ 400,00$ a $\mathrm{R} \$ 700,00$, enquanto em Goiás uma família pode gastar entre $\mathrm{R} \$ 300,00$ e $\mathrm{R} \$ 800,00$ (ANDIFES, ${ }^{4}$ 2010).

Esse significativo investimento das famílias em escolas da rede privada tem por objetivo o sucesso no vestibular, que ainda é o processo de seleção mais utilizado, uma vez que $72,5 \%$ dos ingressos nas universidades brasileiras ocorrem por esse processo (INEP, 2008). Todavia, os resultados dos estudantes no Exame Nacional do Ensino Médio (Enem) têm sido utilizados como meio complementar do vestibular para o acesso às IES e sua utilização pode se intensificar nos próximos anos. Em 2009, o Ministério da Educação apresentou uma proposta visando à reformulação e utilização do Enem como forma de seleção unificada para o acesso às universidades públicas federais.

No entanto, o investimento público nos diferentes níveis de ensino (fundamental, médio, superior) é modesto e privilegia o ensino público superior. Dessa maneira, para ter uma chance de se matricular em uma universidade pública, é preferível que as crianças sejam escolarizadas na rede privada durante o ensino fundamental e médio. A Tabela 1 a seguir, mostra que o investimento público em 2008, para os primeiros quatro anos do ensino fundamental (anos iniciais), é cinco vezes menor que o investimento público no ensino superior.

A análise do investimento público por aluno no ensino fundamental, quando comparado com o custo da rede privada, demonstra uma diferença significativa e permite evidenciar a má qualidade do ensino público. O total das mensalidades pagas por uma família durante um ano é, em média, três vezes ${ }^{5}$ maior do que o Estado gasta com esse mesmo aluno.

4 Associação Nacional dos Dirigentes das Instituições Federais de Ensino Superior.

5 Este cálculo foi realizado para o conjunto do ensino fundamental e médio, adotando como exemplo uma escola privada confessional de Curitiba. 
Tabela 1 - Estimativa do investimento público direto em educação por estudante em R\$ - Brasil 2000-2008

\begin{tabular}{|c|c|c|c|c|}
\hline \multirow[b]{2}{*}{ Ano } & \multicolumn{2}{|c|}{ Ensino Fundamental } & \multirow[b]{2}{*}{ Ensino médio } & \multirow[b]{2}{*}{ Ensino superior } \\
\hline & Anos iniciais & Anos finais & & \\
\hline 2000 & 1.365 & 1.393 & 1.324 & 15.341 \\
\hline 2001 & 1.349 & 1.518 & 1.506 & 15.161 \\
\hline 2002 & 1.576 & 1.463 & 1.060 & 14.374 \\
\hline 2003 & 1.526 & 1.450 & 1.217 & 12.594 \\
\hline 2004 & 1.638 & 1.656 & 1.133 & 12.749 \\
\hline 2005 & 1.833 & 1.746 & 1.146 & 12.965 \\
\hline 2006 & 2.019 & 2.217 & 1.568 & 13.076 \\
\hline 2007 & 2.408 & 2.509 & 1.837 & 13.861 \\
\hline 2008 & 2.761 & 2.946 & 2.122 & 14.763 \\
\hline
\end{tabular}

Fonte: INEP/MEC, 2008.

Esse resultado retrata um problema na divisão do investimento público em educação no que diz respeito aos diferentes níveis de ensino. $\mathrm{O}$ ensino superior público acolhe, geralmente, alunos oriundos das classes privilegiadas, que passaram pelo ensino fundamental e médio privado.

Os filhos das classes desfavorecidas, que normalmente frequentam o ensino fundamental e médio público, não estão, em grande parte dos casos, preparados para passar nos processos seletivos das universidades públicas. Assim, eles se veem obrigados, se quiserem prosseguir seus estudos no ensino superior, a buscar as IES privadas. O que eles gastam com esse ensino é comparável com o que as classes média e alta investem no ensino fundamental e médio privado. Em outras palavras, o poder público gasta mais com a educação dos grupos favorecidos do que com os filhos e filhas das classes desfavorecidas.

O caso da Universidade de São Paulo (USP), a instituição pública superior mais importante do Brasil, ilustra o baixo percentual de alunos provenientes do ensino médio público. Em 2009, 30\% (3.157) dos 
estudantes que integravam essa universidade eram procedentes da rede pública. Em 2010, o percentual caiu para 26\% (2.717). Esse percentual corresponde ao observado em 2006, antes da introdução na USP de um sistema de bônus favorecendo os alunos do ensino público. Em outros termos, as políticas públicas para ajudar os alunos mais desfavorecidos não permitiram desestabilizar as desigualdades estruturais entre os diferentes grupos sociais (FOLHA DE SÃO PAULO, 2010a).

A incapacidade das políticas públicas visando, em princípio, a grupos desfavorecidos, de reduzir as desigualdades educacionais, é ilustrada pela utilização do Enem no Programa Universidade para Todos (ProUni), criado em 2004. Esse exame, criado em 1998, tem como objetivo avaliar as competências e os conhecimentos dos alunos no final do ensino médio. Tal exame é utilizado, total ou parcialmente, como critério para o ingresso no ensino superior por 500 IES. Apenas $8 \%$ das escolas melhor classificadas no Enem são públicas. As escolas particulares oferecem um ensino que permite aos alunos obter melhor desempenho no Enem (FOLHA DE SÃO PAULO, 2009).

De acordo com Castro (2000), o Brasil apresenta uma taxa de escolarização bruta no ensino superior extremamente baixa, se considerarmos a faixa etária alvo, de 20 a 24 anos. No quadro geral do País, o acesso a esse nível de ensino permanece ainda relativamente elitizado: 14, $8 \%$. Os indicadores são ainda mais desfavoráveis no Norte e no Nordeste, onde, apesar do aumento do acesso ao ensino fundamental, poucos alunos têm alcançado o ensino médio e uma parcela ainda menor chega ao ensino superior. Nessas regiões, o aumento do número de matrículas ocorreu especialmente na rede privada, segundo as Sinopses Estatísticas do Ensino Superior 2000-2008, do Inep.

As estatísticas do MEC/INEP (2008) mostram a distribuição geográfica desigual das instituições de ensino superior entre os setores público e privado. O maior número de instituições está localizado no Sudeste: $44 \%$ das instituições públicas e 47,8\% das instituições privadas estão situadas nessa região. A Região Sudeste é sem dúvida a mais populosa do País, mas isso não explica nem justifica a grande concentração de 
universidades, pois quase metade delas encontra-se nessa região. A explosão de cursos de graduação observada no setor privado está relacionada à LDB/1996 (Lei de Diretrizes e Bases da Educação). Durante o período de 1996-2006, o setor privado passou por um crescimento no número de cursos de mais de $324,2 \%$, e o setor público, mesmo que tenha passado por um crescimento significativo, representou apenas $120 \%$ (DUARTE; CASTANHEIRA, 2009).

A fim de ir além de uma análise histórica e comparativa das ligações entre os setores do ensino público e privado, é imprescindível confirmarmos a tese principal e inovadora deste artigo, concernente aos mecanismos de indefinição das fronteiras entre esses dois setores.

\section{A indefinição crescente das fronteiras entre os setores educacionais}

Analisaremos a seguir a indefinição atual dos limites entre as redes pública e privada.

Para além do clássico financiamento público do ensino privado, outros mecanismos mais sutis são observados: a compra pela rede pública de material pedagógico produzido pela rede privada (apostilas, por exemplo), bem como professores que acumulam cargos nas duas redes. Trata-se, portanto, de analisar, de um lado, em benefício de quem ocorre a indefinição dessas fronteiras; e, de outro, mostrar como ela se constitui no principal mecanismo de manutenção das desigualdades educacionais no Brasil.

A análise das relações entre as redes pública e privada e a contribuição destas para a gênese das desigualdades, levou alguns autores brasileiros a utilizarem a criatividade para ilustrar esse fenômeno. Cunha (2007) usa o termo "meandro" para ilustrar as relações entre o Estado e o mercado na educação. Davies (2009) fala de "privatização por omissão". Acreditamos que a ideia de indefinição de fronteiras é apropriada e pertinente para analisar a construção das desigualdades educacionais no Brasil. Essa indefinição permite diluir responsabilidades, especialmente aquelas do Estado e das elites políticas. 
Do nosso ponto de vista, essa indefinição das fronteiras entre os setores de ensino público e privado, responsável em parte pelas desigualdades, passa por cinco mecanismos principais:

a) a legislação favorável ao ensino privado;

b) o financiamento público em favor do setor privado;

c) as parcerias público/privado;

d) o fornecimento, ao ensino público, de material pedagógico formatado (apostilas) pelo setor privado;

e) o trânsito de estudantes e professores do público para o privado e vice-versa.

Discutiremos na sequência esses cinco mecanismos.

\section{a) Uma legislação favorável ao ensino privado}

Inicialmente, é importante salientar que o poder público brasileiro não está ausente da educação, ao contrário, se faz continuamente presente, em especial financiando, avaliando e regulamentando. Durante o regime militar (1964-1985), a iniciativa privada no setor educativo foi encorajada. Como destaca Cunha (2007), o regime militar tinha afinidades político-ideológicas com os promotores da privatização da educação. Com o retorno gradual da democracia, nos anos 1980, a legislação continuou a apoiar a iniciativa privada. Apesar de haver uma regulamentação do setor privado, ele não sofreu qualquer prejuízo, ao contrário, foi reforçado. A legislação brasileira distingue dois tipos de instituições de ensino privado: instituições privadas sem fins lucrativos (escolas religiosas confessionais, filantrópicas ou comunitárias) e instituições privadas stricto sensu. As primeiras gozam de uma série de privilégios, tais como isenção fiscal e empréstimos com baixas taxas de juros pelo Banco Nacional de Desenvolvimento Econômico e Social (BNDES). No entanto, uma vez que os dois tipos de instituições privadas se beneficiam de uma grande 
autonomia de gestão e orientação, é legítimo perguntar onde se situa a fronteira entre as duas.

As instituições confessionais ou filantrópicas buscam se aproximar do status das instituições públicas para poderem ter acesso aos fundos públicos. Elas se declaram "de utilidade pública" não estatais, graças ao seu caráter não lucrativo. A flexibilidade proporcionada pela LDB/1996 favoreceu o setor privado, que busca apenas o lucro por meio da educação. As grandes empresas têm investido no setor com o único propósito de ganhar e aumentar seu capital financeiro. Os alunos tornaram-se clientes/ produtos e são negociados, em operações de compra e venda, pelas instituições privadas de ensino por um valor médio de 2.500 dólares.

Ainda mais: a educação tornou-se uma mercadoria e permite às empresas terem sucesso nas suas aplicações na bolsa de valores. A valorização do capital permite a compra progressiva de pequenos estabelecimentos, formando assim grandes empresas, tais como a Anhaguera Educacional S.A., ${ }^{6}$ a primeira empresa de ensino a aderir ao mercado da bolsa de valores no Brasil, em 2007 (CHAVES, 2009).

\section{b) O financiamento público do setor privado}

Uma das iniciativas da política educacional que ilustra bem os privilégios concedidos ao setor privado diz respeito ao ProUni. Se a ideia original do programa era generosa, na medida em que visava a aumentar o acesso ao ensino superior das camadas mais pobres da população (famílias pobres, afro-brasileiros, indígenas), a execução do programa demonstra, todavia, uma alta captação dos recursos públicos pelo setor privado

6 De acordo com artigo publicado na Folha de São Paulo (2010b), essa empresa atualmente escolariza mais de 300 mil alunos. Ela tem tentado convencer o diretor do Google Brasil a aumentar sua participação no mercado de educação e desenvolver tecnologias da informação e da comunicação na educação. A empresa tem como objetivo uma expansão agressiva para os próximos dez anos, visando a atingir um faturamento de $\mathrm{R} \$ \$ 1$ bilhão, ou seja, um aumento de $40 \%$ em relação ao faturamento atual. 
por meio do financiamento estatal da educação. O ProUni funciona da seguinte maneira: as instituições de ensino superior privadas que oferecem vagas gratuitas a estudantes carentes recebem, como contrapartida, isenções fiscais. O programa que poderia se limitar às privadas sem fins lucrativos foi estendido para instituições com fins lucrativos (CUNHA, 2007).

Entretanto, uma política alternativa ${ }^{7}$ teria permitido às univeridades públicas oferecerem vagas aos estudantes carentes, dando-lhes os meios e recursos indispensáveis para o bom funcionamento dos programas de formação.

\section{c) Parceria público/privado}

Peroni (2006) analisou os efeitos perversos da indefinição das fronteiras entre os setores público e privado, tomando como exemplo duas ONGs brasileiras: Alfabetização Solidária (Alfasol) e Instituto Ayrton Senna (IAS). Apesar de a Alfasol apresentar-se como uma ONG sem fins lucrativos, o Tribunal de Contas da União (TCU) a considera um programa do governo federal. A implementação e a gestão do programa são privadas, mas o principal financiamento é público. Com relação ao IAS, que é também uma ONG sem fins lucrativos, Peroni (2006) analisou seu programa 'Vencer', que visa a melhorar a qualidade da aprendizagem dos estudantes do ensino público. Essa ONG recebe não somente financiamento público direto, mas também um financiamento indireto por meio de isenção fiscal concedida às empresas parceiras do programa. Por que tanto investimento público em instituições não estatais (ONGs)?

Neste período particular do capitalismo, em que se constata a crise do Estado, que, por ineficiência, gastou demais com políticas sociais, a estratégia em voga é diminuir o papel do Estado, transferindo, cada

7 O programa Reestruturação e Expansão das Universidades Federais (Reuni), lançado em 2007, visa ao aumento do número de vagas nas universidades federais. 
vez mais, a coordenação e a execução das políticas para a gestão privada, considerada como sinônimo de eficiência (PERONI, 2006, p. 120).

Constatamos, ainda, que uma das consequências da parceria público/privado no setor educacional é uma tendência das formas de gestão privada para se instalar no setor público (descentralização, autonomia, accountability, resultados, controle, educação a distância, etc.). Segundo Frigotto e Ciavata (2003), descentralização e autonomia são mecanismos de transferência para os agentes econômicos, sociais e educacionais da responsabilidade de competir no mercado de venda de seus produtos ou serviços. A privatização representa o máximo do mercado e o mínimo do Estado. Em outras palavras, o Estado desarticula o patrimônio público e privatiza os serviços públicos, que eram considerados como um direito do cidadão. O mercado se apresenta como um regulador exclusivo de direitos. Esses autores argumentam que a ditadura da ideologia neoliberal conduzirá o debate, sobre a educação e a formação para o setor empresarial, que ajudará a definir orientações para a educação. Serão os empresários que definirão as competências a serem avaliadas ao fim do ensino médio e profissional.

\section{d) Fornecimento, para o ensino público, de material pedagógico formatado (apostilas) pelo setor privado}

Abordaremos a seguir o quarto mecanismo por meio do qual as fronteiras entre o público e o privado tornam-se cada vez mais indefinidas no Brasil. Trata-se do fornecimento, pelas instituições privadas, de ensino de material pedagógico para as escolas públicas. Esse material é pomposamente chamado de 'sistema de ensino', uma vez que visa a uma entrega de conteúdos de ensino que abrangem vários anos escolares. Adrião et al. (2009) analisaram os dados disponíveis sobre esse fenômeno em 645 municípios do Estado de São Paulo, no período de 1997 a 2006. Seus resultados são esclarecedores. Os municípios, sobretudo 
aqueles com menos de 50 mil habitantes, têm a tendência de buscar com as empresas privadas uma variedade de recursos para o ensino: materiais pedagógicos para professores e alunos (apostilas e CD-ROMs), formação continuada de professores e monitoria para utilização do material pedagógico. As empresas privadas não se contentam em ser apenas fornecedoras de materiais, mas intervêm na formulação e orientação das políticas educativas municipais.

As escolas públicas que utilizam apostilas têm adquirido certo prestígio com a clientela da classe média baixa, incapaz de frequentar o ensino privado de qualidade. Em São Paulo, mais de um terço dos alunos das escolas municipais possui orientação pedagógica vendida por grupos privados. Os distritos escolares públicos utilizam os fundos federais para pagar parcerias com empresas privadas que fornecem equipamentos e a formação de professores a um custo de $\mathrm{R} \$ 145,00$ a $\mathrm{R} \$ 260,00$ por aluno, por ano (TÓFOLI, 2006). Essa aquisição visaria a melhorar a educação e/ ou reduzir o fracasso escolar.

De acordo com Adrião et al. (2009), há um número significativo de Municípios do Estado de São Paulo que declaram ter adquirido algum ‘sistema de ensino' de instituições privadas (161).

Os mesmos(as) autores(as) destacam o fato de que os menores municípios são mais vulneráveis ao ataque mercantil do setor privado. Além disso, o material entregue é de má qualidade e não é comparável ao das escolas privadas. Os autores evidenciam, ainda, a existência de um monopólio de quatro empresas privadas nesse mercado lucrativo (duas de São Paulo: Objetivo e COC; e duas do Paraná: Positivo e OPET).

Podemos observar que as instituições de ensino privado mais poderosas, como Positivo e Objetivo, que fizeram fortuna com os cursos de preparação para os processos seletivos (vestibular), penetram no mercado público de material escolar. Outras instituições, como as escolas maristas ligadas à Igreja Católica, também fazem parte desse grupo. Para superar a baixa no recrutamento de novos alunos no ensino fundamental e médio, a rede privada ataca o mercado de publicação educacional com foco nos milhões de alunos de escolas públicas. Essa tendência é facilitada 
pela fragilidade do setor de publicação educacional público no Brasil, comparado ao de países emergentes, como Índia, China ou Indonésia.

A utilização do sistema pedagógico de ensino privado proporciona vantagens financeiras e eleitorais para as elites locais. Irregularidades nas transações são relatadas periodicamente à justiça. Há dois anos, o Tribunal de Contas do Estado (TCE) de São Paulo emitiu regulamentação que exigiu dos municípios a organização de licitações públicas para a compra de material pedagógico. Em um artigo publicado pelo jornal Valor Econômico, de São Paulo, Thereza Adrião (2009) aponta que a utilização da apostila do sistema privado na educação pública era vista como uma moeda de troca eleitoral. O material adquirido é modificado assim que a oposição ganha as eleições, o que provoca uma instabilidade na política de educação municipal. As parcerias entre o setor privado e as escolas públicas em São Paulo coloca múltiplos problemas:

1) falta controle social e técnico;

2) fragilidade conceitual e pedagógica dos produtos;

3) duplo pagamento pelo mesmo serviço, uma vez que o Ministério da Educação fornece gratuitamente material didático;

4) qualidade do ensino submetido à lógica do lucro;

5) padronização dos conteúdos e dos programas como os únicos parâmetros da qualidade da educação.

A discussão concernente às apostilas tem a ver com a menor autonomia do professor. Com a utilização massiva desse material, o ensino torna-se rígido, reducionista, embora a sistematização dos conteúdos, ao longo do ano, possa ser útil para alguns alunos.

O ensino apostilado se propõe regulamentar e padronizar as práticas em sala de aula, dando-lhes um ritmo cadenciado, deixando pouco espaço para o pensamento reflexivo e crítico. Isso desprofissionaliza o professor, convertendo-o em usuário zeloso e dócil das apostilas. Poderíamos chamar essa penetração do privado no público de promiscuidade. 


\section{e) A circulação de alunos e professores entre o público e o privado}

A circulação dos alunos entre as redes pública e privada ilustra bem o caráter estrutural das desigualdades educacionais. Examinaremos, para exemplificar, a trajetória de alunos provenientes de diferentes classes sociais (favorecida e desfavorecida) que transitaram do ensino fundamental para a universidade. Geralmente as famílias desses alunos desenvolvem múltiplas estratégias para lhes possibilitar irem o mais longe possível em sua escolaridade.

Alunos originários de uma categoria social favorecida frequentaram, provavelmente, escolas privadas em toda a sua escolaridade, no ensino fundamental e médio. Contraditoriamente, no ensino superior, eles têm grandes chances de passar no vestibular de uma universidade pública. Os alunos de um grupo social desfavorecido, frequentaram durante o ensino fundamental e médio uma escola pública. Pode ser que eles tenham optado no ensino médio por uma escola privada, a fim de aumentar suas chances de passar no vestibular. Para os estudos no ensino superior, seguiram um curso no setor privado.

Observando esses jovens, verificamos que o financiamento público, durante suas trajetórias escolares, se cruza uma, vez que uns passaram do privado para o público e outros do público para o privado.

Como o gasto médio público para um estudante do ensino superior é muitas vezes superior ao gasto médio público de aluno do ensino fundamental ou médio, constatamos que o Estado brasileiro gastou mais com os alunos originários da classe favorecida que com os alunos provenientes de famílias carentes. Além disso, as despesas com o ensino em escola privada para as famílias de ambos os estudantes são equivalentes, pois o valor gasto por uma família da categoria social favorecida no ensino fundamental e médio corresponde ao investimento do aluno de uma camada desfavorecida no ensino superior privado. Ressaltamos ainda que a duração do ensino superior privado é, muitas vezes, prolongada, visto 
que os alunos precisam trabalhar para se sustentar. A taxa de abandono também é alta, o que não impede a rede privada de colher benefícios.

Mesmo se essa comparação é sumária e não leva em conta a possibilidade da obtenção de bolsas para estudantes de condições modestas, ela corresponde a uma injustiça flagrante do sistema educacional, que consiste no acolhimento de estudantes provenientes de grupos favorecidos no setor universitário público.

O trânsito cotidiano da rede pública para a privada e vice-versa, de muitos professores brasileiros, foi destaque no estudo de Akkari e Pompeu (2010). Esse estudo demonstrou não somente o acúmulo necessário de dois cargos pelos professores, em ambas as redes, mas também as diferentes modalidades de compromisso no setor público e no privado. No privado, os professores são submetidos a mecanismos de controle rigorosos, o que significa dizer, paradoxalmente, que o preço de um bom comprometimento dos professores no setor privado é acompanhado por um descompromisso com o setor público.

\section{Em direção a uma maior regulação das redes de ensino}

Abordaremos, agora, a possibilidade de uma nova regulamentação das relações entre as redes pública e privada de ensino por meio das políticas públicas.

Inicialmente, é difícil prever se o grande investimento público em curso na educação básica poderá fazer retornar, nos próximos anos, pelo menos uma parte das classes média e alta para a rede pública no ensino obrigatório. É importante considerar que é difícil melhorar a qualidade do ensino na rede pública visto que sua degradação ocorre há muito tempo. Além disso, nas grandes cidades, a degradação não é apenas pedagógica, ela é também de segurança, na medida em que a violência urbana não poupa as escolas públicas.

Quanto à reforma dos processos seletivos de acesso ao ensino universitário, iniciada pelo Ministério da Educação, sabemos que ela encontrou resistência de diferentes atores: universidades, pais, etc. Cunha 
(2007) aponta que as forças em conflito que determinam a segmentação do sistema educacional brasileiro são o Estado (Ministério da Educação, Conselho Nacional de Educação, Conselho Nacional de Secretários de Educação dos Estados, os dirigentes municipais da educação, as instituições públicas de educação) e o mercado. Esse último compreende as instituições privadas de ensino e suas entidades representativas. No cruzamento do mercado com o Estado, Cunha (2007) coloca as entidades corporativas. Nesse panorama de forças, Cunha subestima o papel-chave desempenhado pelas autoridades eleitas e pelas elites políticas, independente de sua importância e do nível territorial no qual elas representam os cidadãos (dos eleitos municipais ao Presidente da República).

Esses eleitos são os principais atores que orientam a legislação escolar e as finanças públicas. De suas ações dependerão as condições de enquadramento nas quais o setor privado vai operar, mas também a maneira como serão utilizados os gastos públicos em educação. Os eleitos são também consumidores de educação. Por um momento, imaginemos que eles optem, até por coerência, por matricular seus filhos em escolas públicas, como proposto pelo senador Cristovam Buarque em um projeto de lei que poderia ter mudado a cara da educação no Brasil se não tivesse sido engavetado no Congresso.

Além disso, professores e seus representantes são uma força de peso na possibilidade de consolidar e desenvolver o setor público em educação. A mesma coerência pode ser igualmente esperada deles enquanto usuários e defensores da escola pública. Que credibilidade pode ter um professor da rede pública que reclama pela melhoria da qualidade do ensino público, se ele matricula seus próprios filhos no ensino privado (Akkari; Pompeu, 2010)? É, portanto, uma aliança necessária entre o Estado, consciente da sua missão de educação pública, e os professores do ensino público, portadores de uma responsabilidade histórica, que pode mudar a estrutura de desigualdade do sistema educacional.

Finalmente, é importante ressaltar que os projetos do Ministério da Educação para garantir novas modalidades de acesso ao ensino universitário (reforma do vestibular) podem permitir que mais alunos provenientes de grupos desfavorecidos entrem em universidades públicas, 
contribuindo assim para diminuir a indefinição das fronteiras e a crescente promiscuidade entre público e privado no Brasil.

\section{Considerações finais}

Neste artigo, buscamos defender a tese da indefinição das fronteiras entre os setores público e privado na educação brasileira. Ficou evidente que a dualidade é um dado histórico desse sistema educacional. Tanto os jesuítas quanto outras instituições religiosas colocaram em prática trajetórias de ensino distintas conforme a classe social.

Consolidado na segunda metade do século XX pelas alianças ideológicas das elites econômicas com o regime militar, o ensino privado tradicional religioso, ao qual se acrescentou um setor privado mercantil e ofensivo, desencadeou uma expansão que não foi freada nem pelo retorno gradual da democracia nos anos 1980, nem pelo governo populista de Luis Inácio Lula da Silva, nos últimos oito anos. Ao contrário, várias mudanças legislativas favoreceram o desenvolvimento de instituições privadas de ensino superior, em particular nos anos 1990. Estas visaram, especialmente, às famílias das classes média e trabalhadora, cujo prolongamento da escolaridade constitui uma esperança de acesso ao emprego e à ascensão social.

Além da circulação intensa, em ambos os sentidos, de estudantes nos setores público e privado (as classes favorecidas abandonam o privado pelo público na transição para o ensino superior, as famílias pobres são forçadas a deixar o público e ir para o privado na transição para o ensino superior), pode-se observar a utilização de fundos públicos para subsidiar o setor privado de diferentes maneiras. Nessa paisagem escolar opaca de fronteiras indefinidas, quem perde são as famílias pobres e da classe trabalhadora, que se esforçam para dar conta das exigências financeiras do mercado da educação. Quanto ao poder público, este parece sobrecarregado e incapaz de desempenhar seu papel de regulador, apesar de alguns esforços no sentido de reduzir as desigualdades educacionais por meio de vários programas (ProUni, Reuni, quotas). 


\section{Referências}

ADRIÃO, T. et al. Uma modalidade peculiar de privatização da educação pública: a aquisição de "sistemas de ensino" por municípios paulistas. Educação \& Sociedade, Campinas, v. 30, n. 108, p. 799-818, 2009.

ADRIÃO, T. Livros e apostilas fomentam disputa PT x PSDB. Jornal Valor Econômico, São Paulo, 16 nov. 2009. Disponível em: <http://www.valoronline. com.br/impresso/especial/101/102835/livros-e-apostilas-fomentam-disputa-pt-x-psdb>. Acesso em: 30 set. 2010.

AKKARI, A.; POMPEU, C. La qualité de l'éducation de base au Brésil: entre politiques éducatives et engagements des enseignants. Raisons Educatives, Genève, n. 14, p. 89-118, 2010.

ALTMANN, H. Influências do Banco Mundial no projeto educacional brasileiro. Educação e Pesquisa, São Paulo, v. 28, n. 1, p. 77-89, 2002.

ASSOCIAÇÃO NACIONAL DOS DIRIGENTES DAS INSTITUIÇÕES FEDERAIS DE ENSINO SUPERIOR - ANDIFES. Preço da mensalidade não mensura qualidade. 2010. Disponível em: <http://www.andifes.org.br/index.php?option=com content\&view=article\&id=3937:preco-da mensalidade-nao-mensura-qualidade \&catid=52\&Itemid=100013 > . Acesso em: 30 set. 2010.

AZEVEDO, F. A cultura brasileira. São Paulo: Melhoramentos, 1971.

BERGER, M. Educação e dependência. São Paulo: DIFEL, 1984.

BRASIL. Lei n. 9.394/96, de 20 de dezembro de 1996. Estabelece as diretrizes e bases da educação nacional. Diário Oficial [da] República Federativa do Brasil, Poder Legislativo, Brasília, DF, 23 dez. 1996. p. 27833. Disponível em: <http://www6.senado.gov.br/legislacao/ListaTextoIntegral.action?id=75723>. Acesso em: 30 set. 2010.

BRASIL. Lei n. 10.836, de 9 de janeiro de 2004. Cria o Programa Bolsa Família e dá outras providências. Diário Oficial [da] República Federativa do Brasil, Poder Legislativo, Brasília, DF, 9 jan. 2004. Disponível em: <http://www.planalto. gov.br/ccivil_03/_ato2004-2006/2004/lei/110.836.htm>. Acesso em: 30 set. 2010. 
BRASIL. Lei n. 11.274, de 6 de fevereiro de 2006. Altera a redação dos arts. 29, 30, 32 e 87 da Lei n· 9.394, de 20 de dezembro de 1996, que estabelece as diretrizes e bases da educação nacional, dispondo sobre a duração de 9 (nove) anos para o ensino fundamental, com matrícula obrigatória a partir dos 6 (seis) anos de idade. Diário Oficial [da] República Federativa do Brasil, Poder Legislativo, Brasília, DF, 6 fev. 2006. Disponível em: <http://www.planalto.gov.br/ccivil_03/_Ato2004-2006/2006/Lei/L11274.htm>. Acesso em: 30 set. 2010 .

CASTRO, M. H. G. As desigualdades regionais no sistema educacional brasileiro. In: HENRIQUES, R. (Ed.). Desigualdade e pobreza no Brasil. Rio de Janeiro: IPEA, 2000. p. 425-458.

\section{CHAVES, V. L. J. Novas configurações da privatização do ensino superior}

brasileiro. Disponível em: <http://www.anpae.org.br/congressos_antigos/simposio2009/351.pdf>. Acesso em: 23 jul. 2009.

CUNHA, L. A. Ensino superior e universidade no Brasil. In: LOPES, E. M. T.; FARIA FILHO, L. M.; VEIGA, C. G. (Ed.). 500 anos de educação no Brasil. Belo Horizonte: Autêntica, 2000.

CUNHA, L. A. O desenvolvimento meandroso da educação brasileira entre o Estado e o Mercado. Educação \& Sociedade, Campinas, v. 28, n. 100, p. 809829, 2007.

CURI, A. Z.; MENEZES-FILHO, N. A. Os determinantes dos gastos com educação no Brasil. Disponível em: <http://www.anpec.org.br/encontro2009>. Acesso em: 23 jul. 2009.

DAVIES, E. Privatização por omissão: a participação das redes estadual e municipais de educação básica no Rio de Janeiro em 2006 na comparação com as redes privadas. Revista HISTEDBR, Campinas, n. 33, 2009. Disponível em: <http://www.histedbr.fae.unicamp.br/revista/edicoes/33/art03_33.pdf>. Acesso em: 23 jul. 2009. 
DUARTE SEGENREICH, S. C.; CASTANHEIRA, A. M. Expansão, privatização e diferenciação da educação superior no Brasil pós-LDBEN/96: evidências e tendências. Ensaio: Avaliação e Políticas Públicas em Educação, Rio de Janeiro, v. 17, n. 62, 2009. Disponível em: <http://www.scielo.br/scielo.php?script=sci_ arttext\&pid=S0104-40362009000100004>. Acesso em: 23 jul. 2009.

FOLHA DE S. PAULO. Só $8 \%$ das escolas "tops" no Enem são públicas. Folha de São Paulo, 29 de abril de 2009. Disponível em: <http://www1.folha.uol.com.br/ folha/educacao/ult305u557634.shtml>. Acesso em: 23 jul. 2009.

FOLHA DE S. PAULO. Acesso desigual. Folha de São Paulo, 12 ago de 2010a.

FOLHA DE S. PAULO. Executivo troca Google por Anhanguera Educacional. Folha de São Paulo, 16 set. 2010b.

FRIGOTO, G. Produtividade da escola improdutiva. São Paulo: Cortez, 2001. FRIGOTO, G.; CIAVATA, E. Educação básica no Brasil na década de 1990: subordinação ativa e consentida à lógica do mercado. Educação \& Sociedade, Campinas, v. 24, n. 82, p. 93-132, 2003.

INSTITUTO NACIONAL DE PESQUISAS EDUCACIONAIS - INEP. Sinopse estatística da educação básica: censo escolar. Brasília, 2000a. Disponível em: <http://www.inep.gov.br/basica/censo/Escolar/Sinopse/sinopse.asp〉. Acesso em: 23 jul. 2009.

INSTITUTO NACIONAL DE PESQUISAS EDUCACIONAIS - INEP. Sinopse estatística da educação superior: censo escolar. Brasília, 2000b. Disponível em: $\langle$ http://www.inep.gov.br/superior/censosuperior/sinopse/default.asp >. Acesso em:23 jul. 2009.

INSTITUTO NACIONAL DE PESQUISAS EDUCACIONAIS - INEP. Sinopse estatística da educação superior: censo escolar. Brasília, 2008. Disponível em: 〈http://www.inep.gov.br/superior/censosuperior/sinopse/default.asp〉. Acesso em: 23 jul. 2009. 
INSTITUTO NACIONAL DE PESQUISAS EDUCACIONAIS - INEP. Investimento público em educação. Brasília, 2010. Disponível em: <http://www.inep.gov.br/ estatisticas/gastoseducacao/despesas_publicas/P.A._paridade.htm >. Acesso em: 23 jul. 2009.

MESQUIDA, P. Hegemonia norte-americana e educação protestante no Brasil. São Paulo: Editeo; Juiz de Fora: EDUFJF, 1994.

MESQUIDA, P. Catequizadores de índios, educadores de colonos, soldados de Cristo: formação de professores e ação pedagógica dos jesuítas no Brasil, de 1549 a 1759, à luz do Ratio Studiorum. In: EDUCERE - CONGRESSO NACIONAL DE EDUCAÇÃO, 9., 2009, Curitiba. Anais... Curitiba: Champagnat, 2009.

O GLOBO. Projeto de lei cria critério social para desempate em vestibular. set. 2010. Disponível em: <http://oglobo.globo.com/educacao/mat/2010/09/17/ projeto-de-lei-cria-criterio-social-para-desempate-em-vestibular-917655208. asp>. Acesso em: 23 jul. 2009.

PERONI, V. M. V. Conexões entre o público e o privado no financiamento e gestão da escola pública. ECCOS: Revista Científica, São Paulo, v. 8, n. 1, p. 111-132, 2006.

TÓFOLI, D. Prefeituras de SP terceirizam a educação. Folha de São Paulo. Disponível em: <http://www1.folha.uol.com.br/folha/educacao/ult305u18312. shtml>. Acesso em: 23 jul. 2009.

RAMALHO, J. P. Prática educativa e sociedade. Rio de Janeiro: Zahar, 1976.

Recebido: 14/12/2010

Received: 12/14/2010

Aprovado: 27/02/2011

Approved: 02/27/2011 